\title{
School health in Europe: a review of workforce expenditure across five countries
}

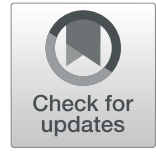

Simon van der Pol ${ }^{1 *}$, Maarten J. Postma ${ }^{1,2}$ and Danielle E. M. C. Jansen ${ }^{1,3}$

\begin{abstract}
Background: Most European countries have implemented a form of school health services (SHS) to provide young children and adolescents with various types of healthcare. No estimations on SHS expenditure for European countries have been published until now. We estimated SHS workforce expenditure in Europe, expected to serve as the main driver of school healthcare costs.

Methods: Using two networks of experts on healthcare provision for children we contacted various country representatives to provide data on the number of professionals working in SHS and salaries. These data were used, together with publicly available data, to estimate annual SHS workforce expenditure on the national level.

Results: We received sufficient data for five European countries, and estimated the SHS workforce expenditure. Nurses were the most widely reported professionals working in this field, followed by doctors and psychologists. Our SHS expenditure estimations ranged from $€ 43,000$ for Estonia to $€ 195,300$ in Norway (per 1000 pupils). For Norway, Estonia, Finland and Iceland, school nurses were the main drivers of SHS expenditure, mainly due to their large numbers, while in Austria, school doctors played the largest role in SHS expenditure.

Conclusions: We estimated the spending on SHS workforce for five European countries, which comprises relatively minor parts of total healthcare spending (0.16 to 0.69\%). Many questions regarding SHS spending in Europe remain, due to a general lack of data on national levels.
\end{abstract}

Keywords: School health services, Child healthcare, Health system comparison, Health expenditure estimation

\section{Background}

Children's happiness and health are known to be important societal values $[1,2]$. It is generally considered that lifetime health outcomes and socioeconomic status are largely determined by an appropriate and stable environment at the start of life [3]. This highlights the importance for society to invest in health equity in life's early stages, that may very well result in rewards as a result of increased health and socioeconomic status. Not only should international human rights incentivise countries to invest in the health of children, but also this economic principle [4,5]. School Health Services (SHS),

\footnotetext{
* Correspondence: s.van.der.pol@rug.nl

'Department of Health Sciences, University of Groningen, University Medical Center Groningen, Hanzeplein 1, 9713, GZ, Groningen, the Netherlands

Full list of author information is available at the end of the article
}

offered in most European countries, educate children from a young age regarding the importance of their health, screen them for various illnesses and provide care for those in need [6].

Recently, SHS care was researched within the Horizon 2020 funded Models of Child Health Appraised (MOCHA) project [6-8]. The organization and composition and content of SHS were explored by sending out questionnaires to country agents, local experts in child and adolescent healthcare, across 30 European countries, of which 28 countries provided school healthcare [6]. In many European countries, direct medical care was found to be a part of SHS, including tasks like the management of chronically ill children and emergency care. In almost all countries, SHS comprised screenings, with a focus on height and weight, as well as vision, hearing and dental 
tests. Another focus in most countries was mental health promotion. Key components of most SHS included preventative care, with a particular focus on communicable diseases with vaccinations, infection control and hygiene surveillance. Preventive measures included vaccinations $(21 / 28)$, referrals to other health professionals $(22 / 28)$, infection control (19/28) and surveillance of the school's hygiene $(18 / 28,6]$. Education was a key area within SHS in many countries as well, such as sex education and the promotion of a healthy lifestyle [6].

Although the urgency for investing in prevention within the healthcare sector is obvious, in European countries expenditure on prevention programmes only accounted for 1-5\% of total healthcare spending in 2016 [9]. SHS expenditure data in general are unknown and its workforce has not been mapped in many countries. For example, the Organisation for Economic Cooperation and Development (OECD), which collects data on national healthcare expenditure, does not report data on SHS spending [10]. One factor of this incompleteness is that some parts of SHS are paid through healthcare budgets and others through education budgets; also, in many countries the responsibility of SHS lies with both local and national governments [6]. Although data on the costs and cost-effectiveness are available for specific interventions in specific countries, the evidence for the costs and cost-effectiveness of the general SHS is limited [11], including the most basic interventions offered (such as screening programmes, education on hygiene and infection prevention).

No studies have been published detailing the costs on a system-wide level for European countries. For the United States, studies determining the cost-effectiveness of running a school-based health centre have been published [12-14]. For specific interventions within schools, European cost-effectiveness studies are available, considering topics like: obesity prevention $[15,16]$, healthy food programmes [17], dental care programmes [18], attention deficit hyperactivity disorder education [19], smoking cessation [20], sexually transmitted infections prevention [21] and school-based immunisation programmes [22, 23]. Many of these interventions are considered to be cost-effective with relatively low budgetary investments [15-23].

As part of our investigations within the context of MOCHA, we examined SHS expenditure and systemwide health effects and concluded data on this topic was lacking [6]. We therefore aim to further investigate SHS expenditure in Europe by estimating the money spent on the SHS workforce, which we expect to be the main driver of SHS costs. With this research, we estimate SHS workforce spending on the national level in countries which are able to provide the necessary data. Additionally, we identify gaps in current knowledge. Better insights into the costs of SHS allow valid costeffectiveness analyses of SHS in the future, potentially further supporting its attractiveness.

\section{Methods \\ Questionnaire}

Building on the country agent network initiated for MOCHA [7] and the economic data collected in work package 3 of the project $[6,8]$, we sent out a questionnaire by email, focusing on the workforce and gross salary of the SHS workforce. This included all countries within the European Economic Area, except for Liechtenstein. The country agents were experts in the field of child healthcare in their respective countries and used indigenous sources to collect data within the MOCHA project. They were selected using a mixedmethods approach and trained by the lead researchers of MOCHA [7]. In case the country agent did not respond, we also contacted the contact listed on the European Union for School and University Health and Medicine (EUSUHM) website [24]. The responses were visualized using a flow chart. Informed consent to use the responses for this research project was acquired from the country agents in writing.

In the questionnaire (see supplementary files), we asked the workforce (numbers) and remuneration estimates of the following SHS professionals (which were identified in previous research [8]):

- School nurses

- School doctors

- Psychologists

- Social workers

- Dentists

- Physical therapists

- Healthcare assistants

- Supportive staff

- Others

For the workforce, questions were asked on the fulltime equivalents (FTEs), the total number of professionals and their type of employment (salaried and/or self-employed). We asked the average gross salary; if this was unknown, we asked the general salary of a professional with 10 years of working experience in the field of SHS.

\section{External data sources}

From the MOCHA project, we knew which SHS professionals were working in which countries: if no numbers were reported in the questionnaire, but the professionals were reported to be working in SHS in previous research $[6,8]$, we considered data to be missing. 
To be able to compare the data between countries, all financial data were converted into 2018 euros and corrected for the number of pupils within each country. From Eurostat we acquired the number of pupils (4-18year olds) for each of the included countries [25]. The consumer price indexes of the various countries were used to incorporate inflation and we corrected differences in currency and purchasing power using purchasing power parities (PPPs) [26, 27]. Labour costs other than wages and salaries were estimated using countryspecific averages [28] as a percentage of the SHS workforce gross income. Total healthcare expenditure for the included countries was used from the OECD [9].

\section{Calculation model design}

Using the collected inputs, we estimated the number of people working in school healthcare and the total salaries. To be able to compare countries, totals were converted to numbers per 1000 pupils and corrected for differences in purchasing power, lastly, all amounts were rounded to the nearest hundreds of euros. The calculation steps for both workforce and expenditure are listed in the online appendix (Supplementary Fig. 1, Online Appendix); external data used for the analyses are reported in Supplementary Table. 1, Online Appendix. These calculations were performed using Microsoft Excel [29].

\section{Results}

\section{Response rate}

Subsequent to sending out the questionnaire to the MOCHA country agents, we received completed questionnaires from Austria, Estonia, Finland, Iceland and Norway. The results and calculations are listed in the online appendix (Supplementary Tables 2 and 3, Online Appendix). For many countries no or insufficient data were available on the national level; this was the case for: Belgium, Bulgaria, Germany, the Netherlands, Portugal, Slovenia, Spain and Switzerland. From the other country agents, no response was received. Additionally, no complete data were received after contacting the EUSUHM network. The results are displayed in Fig. 1, all acquired data are displayed in appendix 1.

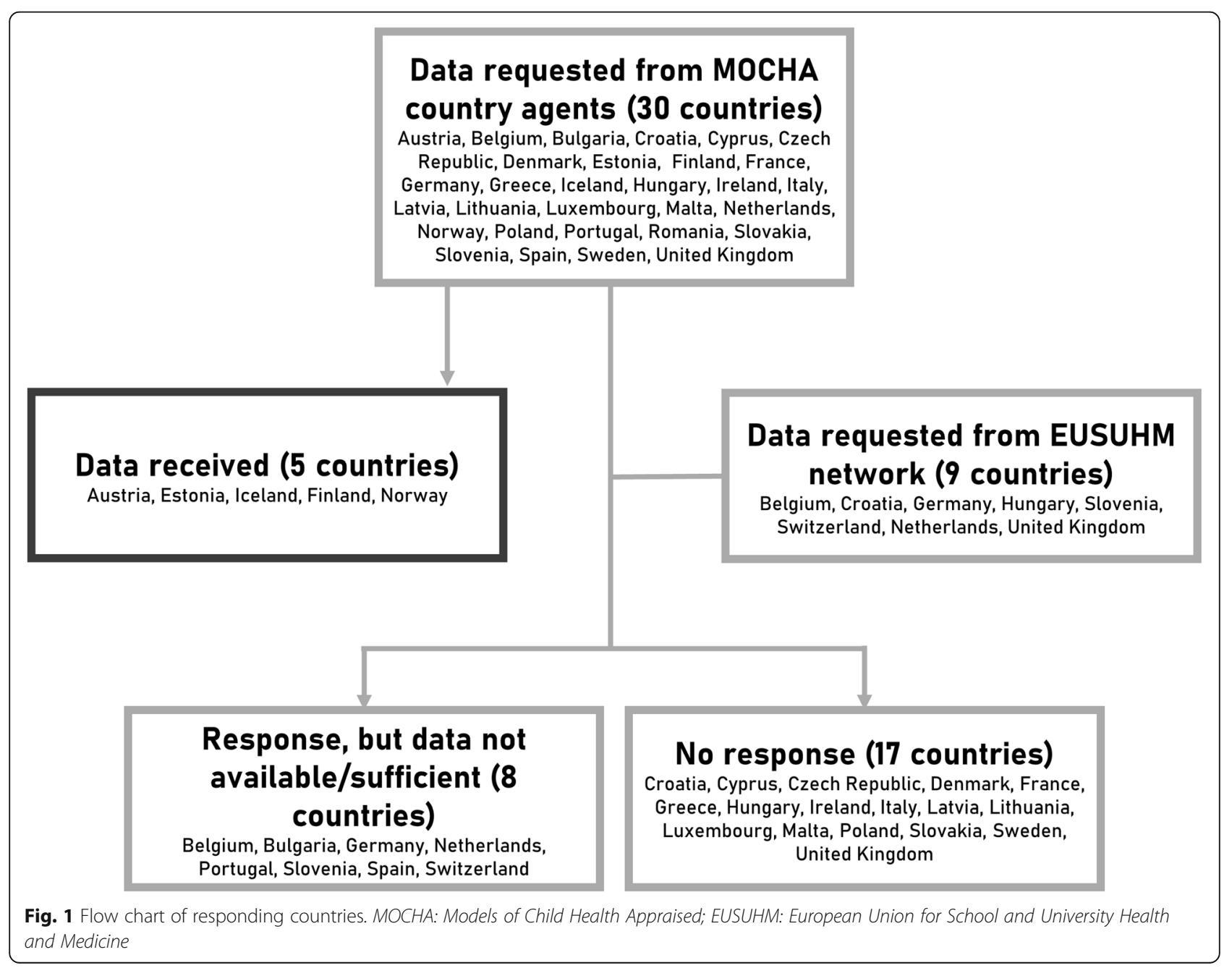




\section{Workforce}

In Fig. 2, the number of health care professionals per 1000 pupils are displayed. Norway reports numbers on social workers, dentists, physical therapists, healthcare assistants and other SHS personnel. School nurses are reported for all included countries, except Austria. Both Norway and Estonia report around 1.4 school nurses on average per 1000 pupils; Finland 1.2 and Iceland reports 0.9. Data are missing for certain countries; no numbers are reported for certain professionals although they are part of a country's SHS [6]: school doctors for Iceland; social workers for Finland and Austria; dentists for Austria; and others for Austria. Salaries of SHS professionals are reported in Fig. 3. In addition to the salaries displayed in Fig. 3, Norway reports salaries of $€ 39,900$ for social workers; $€ 58,600$ for dentists; $€ 38,100$ for physical therapists; $€ 35,800$ for healthcare assistants and $€ 50,300$ for others (administrators/leaders). The salary of school doctors is missing for Iceland [6].

\section{Expenditure}

The total estimated expenditure on salaries per $1000 \mathrm{pu}$ pils is displayed in Fig. 4, as well as the total SHS expenditure as a percentage of the national health budget on the secondary y-axis. Norway, which reports most types of SHS staff, also spends most on SHS: around $€ 195,000$ per 1000 pupils. Finland is estimated to spend around $€ 85,000$; Austria around $€ 56,000$; and for Estonia and Iceland we calculate around $€ 45,000$ per 1000 pupils. These estimations of SHS workforce expenditure range from 0.16 to $0.69 \%$ of total health expenditure for the included countries. All respondents indicate that SHS staff have a salary paid by the government.

\section{Discussion}

Our results show estimated SHS workforce costs for five European countries, ranging from $€ 43,100$ for Estonia to $€ 195,300$ in Norway (per 1000 pupils). For Norway, Estonia, Finland and Iceland, school nurses are the main drivers of SHS expenditure, mainly due to their large

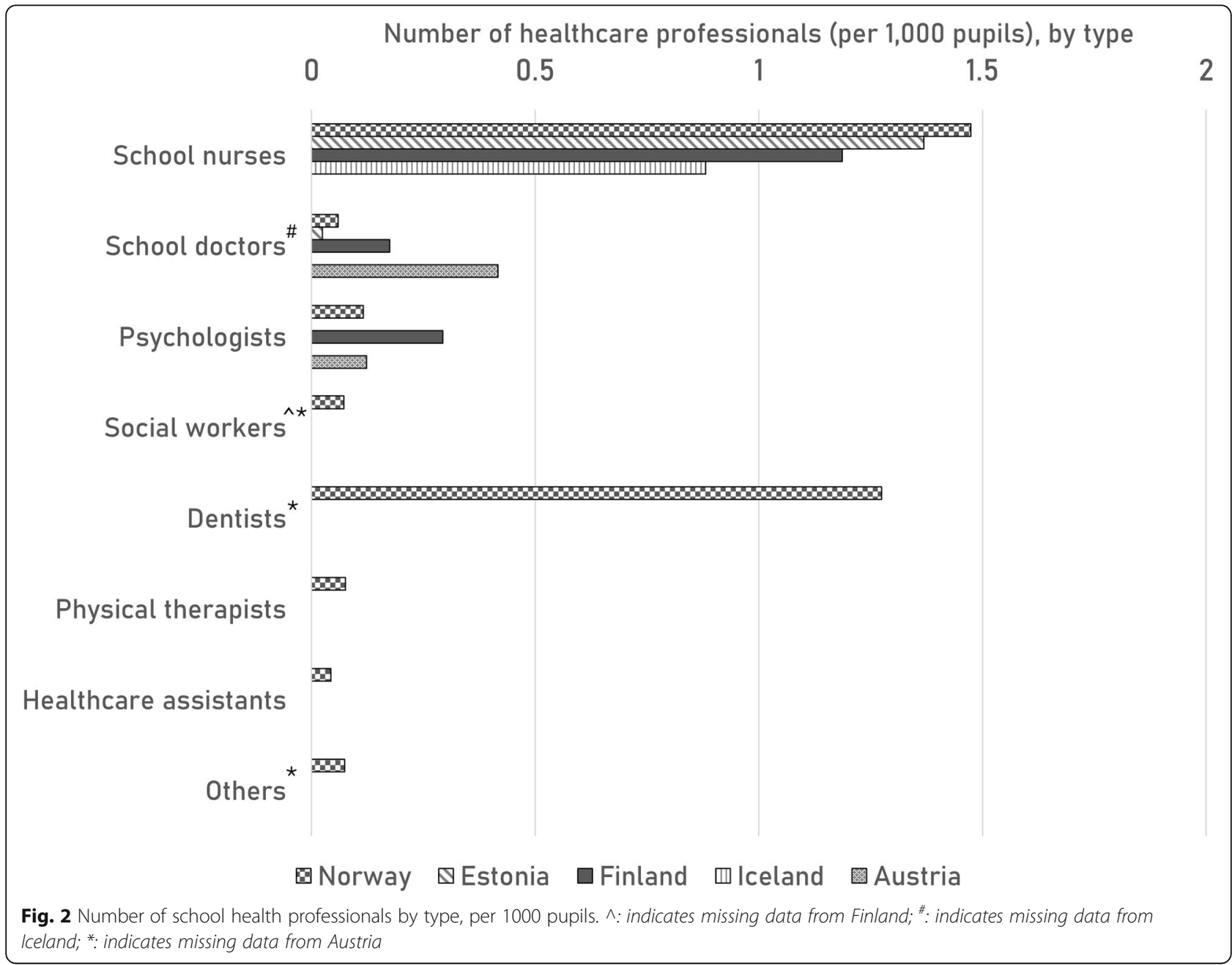




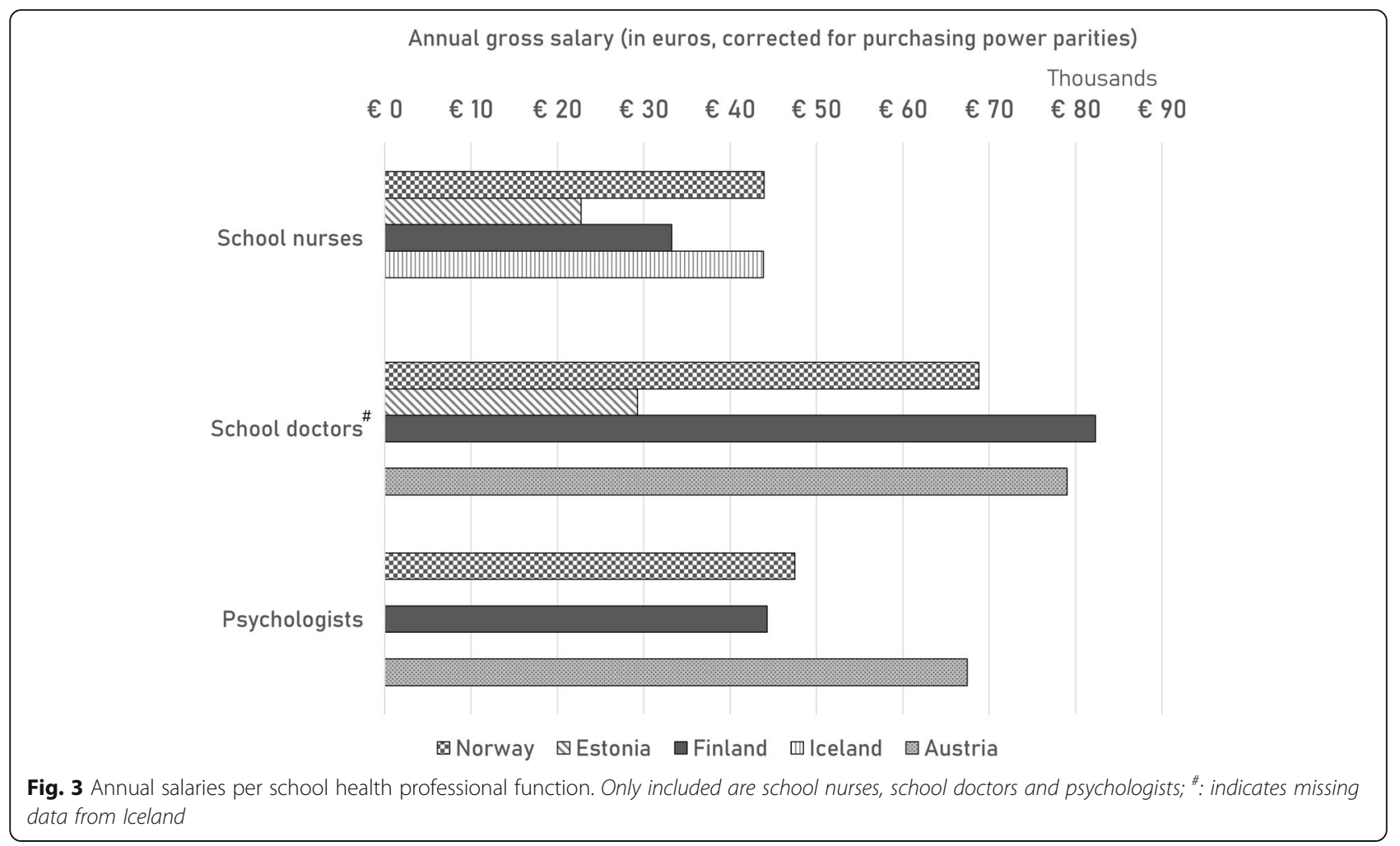

numbers. In Austria, school doctors' salaries contribute to most of SHS workforce spending, with school psychologists playing a relatively minor role due to their modest numbers.

For most countries that are included in our analysis, more health professionals are working indirectly in SHS, making it more difficult to provide estimates of SHS workforce. Examples include nurses in Austria or various health professionals collaborating closely with school nurses in health centres in Iceland. Their work description may include a role in advancing public health for children, however, they are not formally employed in school healthcare. For health systems which are tightly integrated on various levels, it may be difficult to separate the various functions and settings within the system. Many services may be provided to children which are considered a part of SHS in one country yet not in another. For example, dental care in Iceland, which is free for all children, is not considered part of SHS; or social workers who are employed by the municipality in Austria. Frequently, these differences between countries are cultural and historical; the overarching effectiveness of delivering healthcare within school services, as opposed to an alternative primary care setting, remains to be investigated further [30].

As mentioned in the introduction, we hypothesise that workforce spending is the most important driver of school health expenses. No expensive materials are needed, such as expensive medicine or advanced diagnostics [6]. Facility costs are limited, a room inside a school or first-line care facility will suffice. We tried to estimate some of the overhead costs by including supportive staff in the questionnaire, however, no numbers were reported by any of the country agents. Part of the overhead costs is included in the other labour costs, which are reported in Fig. 4. Another possible limitation of this study is the reliance on country agents to report SHS professionals and salaries, however, all country agents have experience with this type of research through the MOCHA project and were trained within this project to provide reliable information [7].

This is the first research project which examines the spending on workforce and wages of SHS personnel in European countries. We estimate this for five countries and find large differences in both workforce and workforce expenditure. However, we are careful in making policy recommendations based on these data, as the aim of this study is not to compare the functioning of SHS between different countries and the full picture regarding child health is missing, as still some data are not available. For most European countries, data on the workforce and associated expenditure remain unknown. Here, we identify a major gap in knowledge on how an important part of European health systems is financed. 


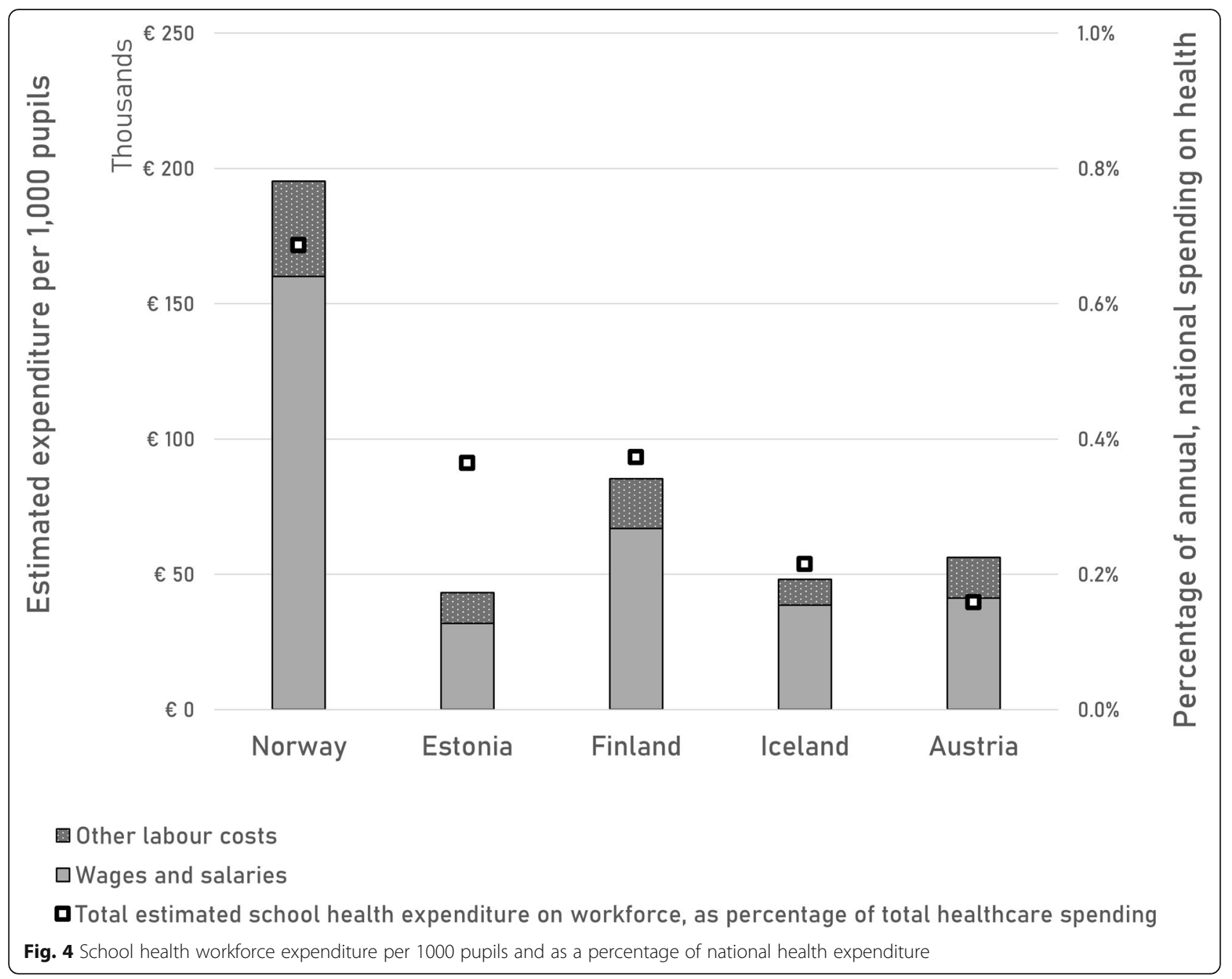

From a policy perspective, we believe this lack of data may be a threat to the maintenance and further development of European school health. Within MOCHA, almost all countries indicated a shortage of staff in SHS [6], however, no data seems to be available to support this claim. Although school healthcare is considered an important part of our health systems as an entry point to target almost all children and adolescents [8], increasingly, there is a focus on quantifying healthcare decisions, e.g. by performing multicriteria decision analyses [31, 32]. This requires standardized data on the total SHS workforce and expenditure, to place specific interventions within school healthcare in perspective and estimate the impact on the overall SHS budget. For certain activities within the health system, such as caesarean sections, MRI exams or length-of-stay for myocardial infarction, rather exact data are available, allowing healthcare professionals, researchers and policy makers to compare different regions and countries [33].
For the future, more accurate measurements of the SHS workforce, performance and expenditure need to be made. We recommend a bottom-up approach; starting on the regional level and working up from there. Consecutively, spending for specific functions (screenings, vaccination, hygienic measures etc.) within SHS can be identified and prioritized for further (cost-)effectiveness analyses. This may provide decision makers with the necessary tools to decide where to invest within healthcare provision for children with the aim of improving health for all.

\section{Conclusions}

We estimate the spending on SHS workforce for five European countries, which is a relatively minor part of total healthcare spending (0.16 to $0.69 \%)$ in these countries. Many questions regarding SHS spending in Europe remain, due to a general lack of data on the national level. 


\section{Supplementary information}

Supplementary information accompanies this paper at https://doi.org/10. 1186/s12913-020-05077-w.

Additional file 1. Online appendix. Online appendix containing additional tables (public data sources, survey results and workforce cost estimations) and a figure detailing the calculation steps.

Additional file 2. Questionnaire. Questionnaire sent to country agents to fill in.

\section{Abbreviations}

SHS: School Health Services; MOCHA: Models of Child Health Appraised; OECD: Organisation for Economic Co-operation and Development; EUSUHM: European Union for School and University Health and Medicine; PPP: Purchasing Power Parity

\section{Acknowledgements}

We would like to thank our contacts within the included countries: Reli Mechtler (Austria), Kädi Lepp (Estonia), Mika Gissler (Finland), Geir Gunnlaugsson (Iceland), Ingrid Sperre Saunes (Norway).

\section{Author's contributions}

SvdP conceptualized and designed the research, collected and analysed the data and drafted the manuscript. MP conceptualized and designed the research and substantively revised the manuscript. DJ conceptualized and designed the research, interpreted the data and substantively revised the manuscript. All authors read and approved the final manuscript.

\section{Funding}

The project is funded by the European Commission through the Horizon 2020 Framework under the grant agreement number: 634201.

\section{Availability of data and materials}

The datasets generated and/or analysed during the current study are available in the University of Groningen repository, https://www.rug.nl/ research/portal/datasets/school-health-workforce-expenditure-across-fivecountries(c1e8871f-7f6f-4ff4-ab5a-bc8328859d68).html

\section{Ethics approval and consent to participate}

This survey was not submitted to an ethics committee, as it did not involve human subjects but dealt rather with procedures and policies. No human subjects were subject to procedures or required to follow rules of behaviour, placing this project outside the scope of applicable Dutch laws (Wet medisch-wetenschappelijk onderzoek met mensen). All survey respondents agreed in writing to participate in this research project. No administrative permissions and/or licenses were acquired for this project.

\section{Consent for publication}

Not applicable.

\section{Competing interests}

M.J. Postma received grants and honoraria from various pharmaceutical companies, all unrelated to this work. The other authors have no conflicts of interest to declare.

\section{Author details}

'Department of Health Sciences, University of Groningen, University Medical Center Groningen, Hanzeplein 1, 9713, GZ, Groningen, the Netherlands. ${ }^{2}$ Department of Economics, Econometrics and Finance, University of Groningen, Groningen, the Netherlands. ${ }^{3}$ Department of Sociology, Interuniversity Center for Social Science Theory and Methodology (ICS), University of Groningen, Groningen, the Netherlands.

Received: 8 November 2019 Accepted: 5 March 2020 Published online: 12 March 2020

\section{References}

1. Case A, Fertig A, Paxson C. The lasting impact of childhood health and circumstance. J Health Econ. 2005;24:365-89.
2. Arpino B, Gumà J, Julià A. Early-life conditions and health at older ages: the mediating role of educational attainment, family and employment trajectories. PLoS One. 2018;13:e0195320.

3. Lantz PM, House JS, Mero RP, Williams DR. J Health Soc Behav. 46:Stress, life events, and socioeconomic disparities in health: results from the Americans' changing lives study, 2005, 274-88.

4. UN General Assembly. UN Convention on the Rights of the Child (UNCRC). 1989. https://www.unicef.org.uk/what-we-do/un-convention-child-rights/. Accessed 18 Apr 2018

5. Venkataramani AS, Brigell R, O'Brien R, Chatterjee P, Kawachi I, Tsai AC. Economic opportunity, health behaviours, and health outcomes in the USA a population-based cross-sectional study. Lancet Public Health. 2016;1:e18-25.

6. Jansen DEMC, Visser A, Vervoort JPM, van der Pol S, Kocken P, Reijneveld SA, et al. School and Adolescent Health Services in 30 European countries: a description of structure and functioning, and of health outcomes and costs. Commission Deliverable. Groningen, the Netherlands; 2018. http://mocha.cc. ic.ac.uk/wp-content/uploads/Deliverable-173.1 Final-report-on-thedescription-of-the-various-models-of-school-health-services-and-adolescenthealth-services-1.pdf.

7. Blair M, Alexander D, Rigby M. The MOCHA project: origins, approach and methods. In: Issues and Opportunities in Primary Health Care for Children in Europe. Emerald Publishing Limited; 2019. p. 1-12. https://doi.org/10.1108/ 978-1-78973-351-820191001.

8. Jansen D, Vervoort JPM, Visser A, Reijneveld SA, Kocken P, de Lijster G, et al. School health services. In: Issues and Opportunities in Primary Health Care for Children in Europe. Emerald Publishing Limited; 2019. p. 219-36. https:// doi.org/10.1108/978-1-78973-351-820191015.

9. OECD. Health expenditure indicators 2019. https://doi.org/10.1787/data00349-en

10. OECD WHO. Eurostat. A System of Health Accounts. Paris: OECD Publishing; 2011. https://doi.org/10.1787/9789264116016-en

11. Langford R, Bonell CP, Jones HE, Pouliou T, Murphy SM, Waters $E$, et al. The WHO Health Promoting School framework for improving the health and well-being of students and their academic achievement. Cochrane Database Syst Rev. 2014:CD008958.

12. Ran T, Chattopadhyay SK, Hahn RA. Economic evaluation of school-based health centers: a community guide systematic review. Am J Prev Med. 2016 51:129-38.

13. Wang LY, O'Brien MJ, Maughan ED. An excel spreadsheet model for states and districts to assess the cost-benefit of school nursing services. NASN Sch Nurse. 2016;31:354-63.

14. Guo JJ, Wade TJ, Pan W, Keller KN. School-based health centers: costbenefit analysis and impact on health care disparities. Am J Public Health. 2010;100:1617-23.

15. Conesa M, Llauradó E, Aceves-Martins M, Moriña D, de Solà-Morales O, Giralt $M$, et al. Cost-effectiveness of the EdAl (Educació en Alimentació) program: a primary school-based study to Prevent childhood obesity. J Epidemiol. 2018;28:477-81

16. Kesztyüs D, Lauer R, Kesztyüs T, Kilian R, Steinacker JM. "Join the Healthy Boat" Study Group. Costs and effects of a state-wide health promotion program in primary schools in Germany - the Baden-Württemberg Study: A cluster-randomized, controlled trial. PloS One. 2017;12:e0172332.

17. te Velde SJ, Lennert Veerman J, Tak NI, Bosmans JE, Klepp K-I, Brug J. Modeling the long term health outcomes and cost-effectiveness of two interventions promoting fruit and vegetable intake among schoolchildren. Econ Hum Biol. 2011;9:14-22.

18. Sköld UM, Petersson LG, Birkhed D, Norlund A. Cost-analysis of school-based fluoride varnish and fluoride rinsing programs. Acta Odontol Scand. 2008;66 286-92.

19. Sayal K, Taylor JA, Valentine A, Guo B, Sampson CJ, Sellman E, et al. Effectiveness and cost-effectiveness of a brief school-based group programme for parents of children at risk of ADHD: a cluster randomised controlled trial. Child Care Health Dev. 2016;42:521-33.

20. Vijgen SMC, van Baal PHM, Hoogenveen RT, de Wit GA, Feenstra TL. Costeffectiveness analyses of health promotion programs: a case study of smoking prevention and cessation among Dutch students. Health Educ Res. 2008;23:310-8

21. Cooper K, Shepherd J, Picot J, Jones J, Kavanagh J, Harden A et al. An economic model of school-based behavioral interventions to PREVENT sexually transmitted infections. Int J Technol Assess Health Care. 2012:28: 407-14. 
22. Trotter $\mathrm{CL}$, Edmunds WJ. Modelling cost effectiveness of meningococcal serogroup C conjugate vaccination campaign in England and Wales. BMJ. 2002;324:809.

23. Joint Committee on Vaccination and Immunisation. Statement on HPV vaccination. Joint Committee on Vaccination and Immunisation; 2018. https://assets.publishing.service.gov.uk/government/uploads/system/ uploads/attachment_data/file/726319/JCVI_Statement_on_HPV_ vaccination_2018.pdf. Accessed 5 Mar 2019.

24. EUSUHM. Members [http://eusuhm.org/index.php/members]. Accessed 2 May 2019.

25. Eurostat. Population by age group. 2019. https://ec.europa.eu/eurostat/ data/database?p_p_id=NavTreeportletprod_WAR_NavTreeportletprod_ INSTANCE_nPqeVbPXRmWQ\&p_p_lifecycle=0\&p_p_state=normal\&p_p_ mode=view\&p_p_col_id=column-2\&p_p_col_pos=1\&p_p_col_count $=2$. Accessed 30 Jan 2019.

26. OECD. Inflation (CPI). 2019. https://doi.org/10.1787/eee82e6e-en

27. OECD. Purchasing power parities (PPP). 2019. https://doi.org/10.1787/ 1290ee5a-en.

28. Eurostat. Wages and labour costs. 2018. https://ec.europa.eu/eurostat/ statistics-explained/index.php/Wages_and_labour_costs\#Gross_wages.2 Fearnings. Accessed 5 Feb 2019.

29. Microsoft. Excel. en. Redmond, WA, United States; 2018. https://www.office. com/. Accessed 10 Apr 2018.

30. Levinson J, Kohl K, Baltag V, Ross DA. Investigating the effectiveness of school health services delivered by a health provider: a systematic review of systematic reviews. PLoS One. 2019;14:e0212603.

31. Thokala P, Devlin N, Marsh K, Baltussen R, Boysen M, Kalo Z, et al. Multiple criteria decision analysis for health care decision making — an introduction: report 1 of the ISPOR MCDA emerging good practices task force. Value Health. 2016;19:1-13.

32. Marsh K, IJzerman M, Thokala P, Baltussen R, Boysen M, Kaló Z, et al. Multiple criteria decision analysis for health care decision making - emerging good practices: report 2 of the ISPOR MCDA emerging good practices task force. Value Health. 2016;19:125-37.

33. OECD. Health at a Glance 2017. OECD Indicators. Paris: OECD Publishing; 2017. https://doi.org/10.1787/health_glance-2017-en.

\section{Publisher's Note}

Springer Nature remains neutral with regard to jurisdictional claims in published maps and institutional affiliations.

Ready to submit your research? Choose BMC and benefit from:

- fast, convenient online submission

- thorough peer review by experienced researchers in your field

- rapid publication on acceptance

- support for research data, including large and complex data types

- gold Open Access which fosters wider collaboration and increased citations

- maximum visibility for your research: over $100 \mathrm{M}$ website views per year

At $\mathrm{BMC}$, research is always in progress.

Learn more biomedcentral.com/submissions 